\title{
Antipuidade tardia como forma da História
}

Uiran Gebara da Silva*

Resumo: Este artigo apresenta uma investigação cujo objetivo é examinar o problema do confronto de paradigmas explicativos a respeito do fim da Antiguidade: a ascensão da Antiguidade Tardia, uma nova Forma da História, e o Declínio do Império Romano. Nos últimos trinta anos, essa visão tem sido progressivamente contestada por historiadores das mais variadas tendências, que defendem desde uma diminuição do impacto da ruptura causada pelo fim do Império, até a completa negação desta ruptura. Fundamentando esse processo, conceitos estruturais da interpretação tradicional, como o de crise, de decadência e de invasões germânicas, perdem seu espaço para outros como a ideia de continuidade da Romania e a de acomodação dos povos germânicos. Essa avaliação busca entender em que medida o fim do século XX influiu nessa mudança na historiografia.

Palavras-chave: Historiografia. Antiguidade tardia. Império Romano. Teoria da História.

O final do século XX esteve pleno de supostas mudanças de paradigmas, de maneira que foi possível que um historiador escrevesse em 1994: "O Iluminismo está morto, o modernismo está morto, o marxismo está morto, o movimento da classe trabalhadora está mor-

\footnotetext{
* Doutorando do Programa de História Social da Universidade de São Paulo. Bolsista Fapesp. Endereço eletrônico: uirangs@usp.br
} 
to... e o autor também não se sente muito bem" (Neil Smith, ${ }^{1}$ apud: SALIBA, 1996, p. 40). Um destes paradigmas, o de O Declínio e Queda do Império Romano, fundamental para a construção da identidade histórica europeia, foi colocado metaforicamente nas cordas. Em fins dos anos 60 do século XX, apareceram alguns estudos que insinuavam a construção de um cenário diferente da transição entre Antiguidade e Idade Média. Foi nas décadas de 80 e 90, contudo, que esta insinuação se consolidou numa nova corrente interpretativa. Este processo se deu através do desenvolvimento próprio das pesquisas sobre a cultura material, a cultura escrita e a arte do Baixo Império e da Alta Idade Média, acompanhando o movimento mais amplo de mudanças dentro da disciplina História que culminou com o "retorno da narrativa" (STONE, 1991; BURKE, 1992). Uma das novidades desta nova perspectiva e ponto fundamental para sua consolidação como novo paradigma é a ascensão de um novo recorte cronológico: a Antiguidade Tardia. Esta mudança na historiografia ainda não se traduziu na nossa consciência histórica mais ampla, digamos, na memória histórica do cidadão ocidental médio (quiçá na do brasileiro), mas teve, porém, grande impacto nos especialistas.

Uma mudança de paradigma assim não deve ser encarada de maneira inocente, sendo necessário que tenhamos clareza do que ela implicou em termos de hierarquização e política dentro da Academia, desde o planejamento de cursos num departamento até a des-tinação de verbas de pesquisa pelas agências de fomento. Ainda assim, essa preocupação deve ser determinada também pela compreensão do mérito historiográfico próprio da nova perspectiva.

\section{I - Paradigmas e Formas}

O conceito de paradigma aqui está sendo utilizado de forma flexível, inspirado nas propostas de Thomas Kuhn, feitas pela primeira vez em 1962 (KUHN, 2006), nascidas de um debate sobre teoria da ciência, voltado para as ciências exatas. Este conceito e seu uso para a compreensão da História como prática científica será articulado aqui à ideia de Formas da História (GUARINELLO, 2003), que não deve ser confundida com a de paradigma, embora seja assim como 
ele uma unidade estrutural de sentido. É, porém, uma unidade estrutural de sentido muito particular. O discurso científico, pela sua própria condição de discurso organizador e disciplinar do conhecimento - incluindo a História Científica (GUARINELLO, 1994, p. 185) - constrói estas estruturas mais amplas, os paradigmas, unidades gerais, definidoras ao mesmo tempo das questões e da explicação de um fenômeno social ou natural. Estas unidades estruturam uma tradição teórica dentro das quais as hipóteses, evidências empíricas, teorias e modelos se articulam (KHUN, 2006, p.29-30). A pertinência para essa investigação do modelo de Khun é a forma como ele tenta dar conta da mudança e da transformação na explicação científica. Há, segundo ele, períodos de ciência normal, nos quais os pesquisadores partem do paradigma estabelecido, desenvolvendo seus problemas e formulando seu corpo teórico e explicativo. No entanto, esse desenvolvimento pode levar a descobertas empíricas, ou incoerências no corpo teórico que podem colocar o paradigma em crise. E é nesse período de crise, que podem surgir outros paradigmas, substituindo o anterior, o que chama de revolução científica (KUHN, 2006, p.77-92). Para a História Científica, o que interessa não é exatamente a arquitetura integral do modelo de Kuhn, apenas a forma geral do seu raciocínio e maneira como ele descreve a crise de um paradigma.

As Formas, porém, não se originaram dentro do discurso da História Científica, estavam em formação junto com a identidade histórica europeia desde o Renascimento e serviram de matéria cultural e ideológica para a construção das estruturas disciplinares da História Científica.

A História Científica é, assim, um jogo interpretativo entre certos modelos e teorias e certos documentos, com base em generalizações ou contextos - as formas - que são admitidos ou aceitos como válidos pelos escritores e seus leitores. E tais formas ou contextos são necessários porque os documentos são sempre singulares e, do ponto de vista de um historiador, não tem sentido em si mesmos. Há vários graus no processo de generalização no trabalho do historiador. Definir um período é um deles: os historiadores assumem que um período específico tem certas características comuns, de modo que 
documentos produzidos numa mesma "época" podem ser relacionados uns aos outros, podem ser comparados, podem dialogar entre si. Quanto mais longo o período, mais rico o diálogo, mais documentos podem ser postos em relação. Por conseguinte, um documento confere ou atribui contemporaneidade a documentos que, rigorosamente, não são contemporâneos. Outra forma de generalização é nomear ou definir uma sociedade, ou uma cultura, ou uma área cultural de modo que documentos atribuídos à mesma sociedade ou cultura possam ser relacionados entre si. E isto mesmo que os documentos tenham sido produzidos por agentes diferentes, para propósitos diversos e sejam de natureza muito diferente (como por exemplo, objetos arqueológicos e textos). (GUARINELLO, 2003, p. 45-46)

As Formas da História, assim, não se justificam - ou não se justificavam - dentro do discurso científico, mas atuam e atuaram sobre ele de fora. Os elementos de arquitetura das Formas se apresentam como coordenadas cronológicas e territoriais, de forma que aquelas naturalizaram processos históricos complexos e diversos numa específica interpretação da história de uma específica sociedade, dando a esta História a pretensão de ser universal (GUARINELLO, 2003, p. 46). Tais formas são o que Jeans Chesneaux chama de quadripartismo histórico: "O quadripartismo nada mais é que uma das versões, e não a melhor, do velho sonho de um 'discurso sobre a história universal" (CHESNEAUX, 1995, p.97).

A partir da capacidade que as ciências humanas modernas têm de fazer o mundo à sua imagem (SAID, 2007, p. 366-367), com as Formas atuando como estruturas pressupostas, indiscutidas e nunca pensadas, a História Científica europeia articulou um paradigma que durou até metade do século XX: a sociedade burguesa - e dentro desta a sociedade europeia - é a mais desenvolvida da humanidade, alcançando validade universal, porque é racional e inventou a modernidade (ou sem eufemismos, o Capitalismo). ${ }^{2}$ Construiu-se a grande narrativa do nascimento do Ocidente, tendo como nexo a História Moderna europeia e,como clímax, a História Contemporânea europeia.

É preciso advertir desde já que este sistema quadripartite de 
organização da história é um fato francês. (...) Mas é talvez na França que a sistematização da história universal numa estrutura rígida, quadripartite, é mais extremada, é mais acabada. Esse quadripartismo cumpre certo número de funções precisas, ao mesmo tempo no nível das instituições universitárias e no nível da ideologia. (CHESNEAUX, 1995, p. 93).

Embora a ascendência do quadripartismo seja francesa, ele também é a regra na academia e no ensino básico e médio de História no Brasil ${ }^{3}$ e em geral na América Latina. E mesmo assim, o que é um fato originalmente francês é especificamente o quadripartismo, não o uso de Formas como generalizações, como estruturas pressupostas.

Para o resto das nações europeias, a estruturação das Formas pode variar: as fronteiras entre Idade Moderna e Contemporânea podem ser inexistentes, como é o caso inglês e estadunidense; menos nítidas, como é o caso da Alemanha; ${ }^{4}$ podem ser atrasadas, como a Itália (que coloca a Idade Contemporânea depois do Congresso de Viena). Embora os caminhos e descaminhos da construção de seus Estados Nacionais e sua transformação em economias capitalistas interfiram na definição de suas respectivas "modernidades", em todos os casos, a diferenciação entre Antiguidade e Idade Média está presente; são, de qualquer maneira, variações do mesmo processo de "sistematização da história universal numa estrutura rígida" e que servem ao mesmo propósito.

\begin{abstract}
A História tradicional do Brasil reforçou a identificação da elite com a Europa e ajudou a apagar as raízes africanas e indígenas do país. Ainda hoje, os índios nativos brasileiros não têm, praticamente, nenhuma História. Isto significa que todas as formas produzem, ao mesmo tempo, memória e esquecimento, visibilidade e invisibilidade (GUARINELLO, 2003, p. 50).
\end{abstract}

Esse esquecimento e essa invisibilidade, parte inerente da escrita da História, podem ser, ainda assim, operados de uma forma mais crítica do que é normal. Assim, "se não é possível passar sem as formas, é necessário determinar com clareza como e porque foram 
criadas e quais seus efeitos para nossa compreensão do passado e da História humana como um todo" (GUARINELLO, 2003, p. 50). A História Universal, como forma de discurso científico da história do mundo como um todo é um produto e um resultado do processo de globalização de uma forma de sociedade. Se a formação dessa sociedade globalizada procedesse sem atritos, sem resistência, se a homogeneização de uma pluralidade de diferentes sociedades e trajetórias humanas ocorresse sem confronto ou crises, a homogeneização do discurso histórico, sob a linearidade das formas, e seu eurocentrismo na consciência histórica destas diferentes sociedades também não enfrentaria crises. Não produziria crítica na consciência histórica, de forma que "(...) esta consciência (...) [abrisse] para os historiadores a possibilidade de produzir visões alternativas, de criar ou escrever outros passados. E isto pode ser útil (e é mesmo necessário) numa época de grandes transformações como a atual. (GUARINELLO, 2003, p. 50)". ${ }^{5}$

\section{II - O paradigma historiográfico de Declínio e Queda do Império Romano}

O Declínio e Queda do Império Romano era um paradigma explicativo do processo histórico expresso pela memória social da sociedade romana. Este paradigma era conformado sob estas duas Formas, a Idade Antiga e a Idade Média, de maneira que a Queda do Império assumia o significado de Fim do Mundo Antigo. Historiadores, a partir do Renascimento (MAZZARINO, 1991, p. 87-104), e com ainda mais ênfase, no Iluminismo (CHESNEAUX, 1995, p. 96), associaram o par mais antigo de Formas à nova forma: a Idade Moderna. ${ }^{6}$ Depois, quando no século XIX, face às transformações oriundas das duas grandes revoluções da modernidade, ${ }^{7}$ a Francesa e a Industrial, era adicionada ao trio a Idade Contemporânea (CHESNEAUX, 1995, p. 96), completava-se uma poderosa construção ideológica, que naturalizava a hipótese dos historiadores europeus de que haveria uma identidade histórica entre o mundo Antigo e a Europa Moderna.

Este paradigma situava o ano de 476 d.C. como o marco cronológico por excelência da transição da Idade Antiga para a Idade Média. Assim, as ideias de Queda ou Declínio eram consolidadas cro- 
nologicamente, como paradigma de interpretação historiográfica, operando uma clivagem entre duas Formas da História (Idade Antiga e Idade Média), ao mesmo tempo oferecendo explicações para a clivagem. Implicitamente, esta operação permitia aos historiadores europeus articularem uma Forma à outra. Ou seja, articular a identidade europeia da História medieval, com a da História do Império Romano. Ainda, e não menos importante, a articulação com a história de Roma também serve de mediação à História do Mundo Grego; História fundamental para a identidade histórica europeia, em tudo que ela significa como mito do nascimento do ocidente: racional, apolíneo, civilizado, indo-europeu ou ariano etc. (BERNAL, 2005; GUARINELLO, 2003, p. 53). O século V da era cristã passou à consciência histórica europeia como o do suspiro final do ocidente do Império, consciência que aos poucos igualava ocidente do Império com Império do Ocidente (Ocidente, como toda instituição, começando com letras maiúsculas), num esforço para tornar o oriente do Império em algo mais "oriental". Se o Império não tivesse caído, como poderia ser reconstruído com Carlos Magno? Se a Antiguidade não tivesse terminado, como poderia ser redescoberta no Renascimento?

Tendo esta articulação das Formas como estrutura primária de sentido, e o paradigma da transição como Declínio ou Queda, os historiadores da Antiguidade e da Idade Média foram formulando questões mais particulares sobre esta transição, conduzidos não só pela apreensão dos eventos e fatos apresentados na documentação, mas também profundamente influenciados por fatores sociais e ideológicos. (MAZZARINO, 1991, p. 205-229; BROWN, 2003, p. 1-34, GEARY, 2005, p. 27-55).

Santo Mazzarino publicou em 1959 um ensaio que servirá de ponto de partida para a problematização feita neste artigo sobre a “ascensão e queda” da noção da Queda e da Decadência do Império Romano. Em seu ensaio, Mazzarino fez uma recuperação de toda a tradição escrita a respeito das ideias de Império Universal e de Decadência ou Queda do Estado. É surpreendente encontrar ambas presentes na Mesopotâmia antiga. O que é mais surpreendente ainda é que a ideia de Decadência é anterior, sendo encontrada em relatos das Cidades-Estado sumérias, enquanto a de Império Universal só aparece depois, com a Monarquia Acadiana (MAZZARINO, 1991, 
p. 13-15). Estas noções aparecem entre as Cidades-Estado gregas e também entre os etruscos (assim como a divisão do tempo em "eras"). Pensadores romanos como Lucrécio já atribuíam a Roma uma situação de decadência, escrevendo no período das Guerras civis. Políbio, ao narrar a consolidação do Estado universal Romano, com sua vitória sobre Cartago, já tinha em vista a possibilidade de sua decadência. É em Políbio que, pela primeira vez, aparece a divisão das causas da decadência em internas e externas (MAZZARINO, 1991, p. 23-31). Assim, estas ideias são antigas, fazendo parte da própria tradição textual estudada pelos historiadores da Antiguidade, sendo, aliás, mais antigas que a própria cidade de Roma e, portanto, mais antigas do que a "Queda de Roma". A existência delas como categoria literária e explicativa teve uma existência prolongada, no sentido de uma tradição formal continuamente recebida e repassada, den-tro das narrativas sobre o destino dos Estados antigos.

O importante aqui não é apontar a ficcionalidade de tal categoria, que, ao se consolidar formalmente dentro de uma tradição literária, teria perdido toda e qualquer referencialidade factual. ${ }^{9}$ Muito pelo contrário, é a preocupação que as elites ligadas a estes Estados antigos tinham com as possibilidades efetivas de destruição de seus Estados, o que permitiu o processo de formalização de tais categorias dentro de uma tradição literária. Assim, estas categorias já estavam presentes na tradição latina escrita, como História, na conformação da memória social daquela sociedade. E, nos registros dos períodos que a historiografia moderna chama de crises do século III e V, estas categorias aparecem de forma clara e atuante (MAZZARINO, 1991, p. 47-62; COURCELLE, 1955; WARD-PERKINS, 2005, p. 13-31).

A apropriação destas categorias (Estado Universal, decadência do Estado, causas internas e externas) por um discurso histórico cristão, seja no fim da Antiguidade com Orósio; ${ }^{10}$ seja na era medieval, implicou sua associação com outra categoria explicativa, a de Juízo de Deus. E a noção de Queda do Estado Romano era inserida em uma estrutura escatológica de eras, na qual o fim não era o do Estado, mas do mundo humano ${ }^{11}$ (MAZZARINO, 1991, p. 67-83).

Ainda, Mazzarino aponta a centralidade que estas categorias da narrativa da queda do Império romano ocupavam no discurso histórico dos reinos bárbaros e da Igreja Católica medievais, enquanto que o 
mesmo não ocorria na escrita da História em Bizâncio e no mundo árabe. Em Bizâncio - significativamente autodenominado Império Romano (STE.CROIX, 1998, p. 7-9) - o Estado não acabou, apenas perdera territórios; no pensamento árabe, tomando como exemplo Ibn Khaldun, reencontra-se uma perspectiva laica na compreensão da queda do Estado - que Mazzarino chama de "única interpretação sociológica da Idade Média para esse grandioso episódio"- que fala de derrota do Estado Romano, tendo em mente a perda por Constantinopla da Síria e do Egito (MAZZARINO, 1991, p. 83-85).

No período do Renascimento, Mazzarino analisa de que forma a criação de uma época moderna, atrelada à perspectiva de Renascimento na Itália, ancora-se na produção das noções de Declínio (inclinatio de Flávio Biondo), ou de Decadência (vaccillatio de Leonardo Bruni) do Império Romano. Ambas as noções pensam o fim do Império como um longo processo, tendo como gênese a perda das características republicanas, o que resultara no enfraquecimento do poder do Estado e do caráter dos romanos. A diferença entre uma e outra reside na perspectiva melancólica da inclinatio de Biondo, na qual o enfraquecimento é sem retorno - uma vez que opera aqui o Juízo de Deus - e a vitória bárbara é apenas o desenlace de uma sociedade condenada. Enquanto que a vaccilatio de Bruni acentua a derrota militar e diminui o veredicto condenatório, aos seus olhos, Roma republicana renascia na Itália do século XV. A força dessa construção de uma continuidade identitária de Roma à Europa renascentista é atestada pela existência de uma voz incômoda, como a de Lorenzo Valla. Ao criticar a doação de Constantino, critica também a de Translatio Imperii, de maneira que, ao seu ver, o imperador em Constantinopla seria o autêntico herdeiro de Roma, enquanto o Império carolíngio seria uma criação pontificia (MAZZARINO, 1991, p.96-97). Mesmo assim, o que prospera na tradição de escrita renascentista sobre Roma é a ideia de Declínio - para a qual a publicação de História secreta de Procópio em muito contribuiu (MAZZARINO, 1991, p.117).

Ao avaliar os estudiosos que vão do renascimento até Gibbon, Santo Mazzarino afirma:

(...) muitos dos problemas que conseguimos arrancar daquele passado de um milênio e meio atrás são os mesmos problemas 
"deles": Constantino se converteu? Em que sentido Juliano se lhe contrapõe? Como o cristianismo alcançou a vitória sobre o mundo clássico? Por que a economia unitária do Império romano se esfacelou? A torrente dos bárbaros abateu-se sobre um mundo que já estava em fase de fragmentação?... Sobre a mesa de estudo dos historiadores, há dez ou oito gerações, encontravam-se os mesmos problemas. O século XVII os intuiu, às vezes os colocou; o XVIII os colocou sistematicamente. Por isso mesmo agora podemos estudá-los, um de cada vez, em sua dialética e em sua formulação, desde aquela época até nossos dias (MAZZARINO, 1991, p. 122).

A afirmação de Mazzarino aponta a continuidade na problemática do Fim do Império e como, do renascimento ao Iluminismo, prepararam-se na escrita da História europeia os elementos componentes do paradigma de Declínio e Queda do Império Romano. A partir dos séculos XIX e XX, dentro de um contexto social radicalmente diferente, a industrialização, os Estados Nacionais produzem uma sistematização documental sem precedentes dos textos antigos e a configuração do discurso histórico em termos científicos - e na sua conformação sob as Formas (como vimos acima). Esta história científica tem de lidar, por um lado, com o problema da identidade nacional e, por outro, com o problema das massas - ou numa outra formu-lação, com o problema da luta de classes (STE.CROX, 1998, p. 31-33). A estes, somaram-se ainda outros ao longo do século XX, como o da cultura popular, ou o da alteridade. Essa continuidade na problemática da História do fim do Império romano teve de se articular a alguns novos problemas que alteraram radicalmente a composição do todo do paradigma.

Neste paradigma explicativo da transição da Idade Antiga para a Idade Média, o instrumental crítico da História atuou de forma a explorar as potencialidades do paradigma até os seus limites. Assim, longe de se estabelecer num sólido consenso, este se desdobrava em uma série de questões, hipóteses e interpretações diversas da transição da Idade Antiga para Idade Média. ${ }^{12}$ Assim, a descrição do paradigma do Declínio e Queda do Império Romano a partir dos seus problemas fundamentais visa a valorizar a elaboração de questões e expli- 
cações específicas na construção do discurso histórico. A consolidação do paradigma pode ser observada a partir da formulação de respostas e tradições explicativas dentro do campo da História sobre Roma. Há, no entanto, outra dimensão pertinente para esta descrição que aparecerá de forma fragmentada: a das tradições nacionais de historiografia.

O núcleo deste paradigma é a ideia de que o fim do "Império Romano do Ocidente" e a "bizantinização" do "Império do Oriente" marcam o início da Idade Média. A partir desta ideia central, e devido ao seu caráter estruturante das outras questões, vem o problema das causas do declínio do Império romano. As interpretações sobre o sentido e as causas do fim do império no ocidente ainda eram divididas em externas - as invasões de povos bárbaros - ou internas - a decadência cultural ou econômica da sociedade romana. Esta dualidade explicativa de origem polibiana foi sistematizada em termos sociológicos, em sua forma mais plena, num pequeno ensaio publicado em 1896: As causas sociais da decadência da cultura antiga, de Max Weber (WEBER, 1983, p. 37). Weber tomava partido das causas internas, a partir da oposição entre uma civilização urbana e uma civilização rural. A queda do Império era a dimensão política da transformação gradual e lenta da economia monetária do Império em uma economia natural. Transformação calcada na crise do abastecimento e progressiva escassez do trabalho escravo. ${ }^{13}$ Com respeito à Historiografia alemã, ao centrar sua atenção na esfera econômica e política, Weber se contrapõe por um lado à defesa das instituições germânicas vitoriosas e superiores de Leopold Ranke e, por outro, à ideia da decadência racial de Otto Seeck (MAZZARINO, 1991, p. 137-157), ambas formuladas a partir da monumental construção filológica dos Monumenta Germaniae Histórica, no século XIX (GEARY, 2005, p. 40-49).

$\mathrm{Na}$ Historiografia francesa, a explicação através das causas internas aparece claramente em $O$ fim do mundo antigo e o princípio da Idade Média de Ferdinand Lot. Uma obra que foi escrita inicialmente como tentativa de síntese da questão em 1927 - fazendo parte da mesma coleção que Sociedade Feudal de Marc Bloch - tornando-se referência historiográfica. Lot escrevera que as crises econômicas do século III eram expressões das transformações pelas quais o Império romano passava internamente e que, assim, já o anunciavam um "estágio preparatório, uma antecâmara para a Idade Média" (LOT, 
1982, p. 60). Diminuía, assim, o papel dos povos bárbaros e valorizava as dificuldades que o Estado experimentava: a incapacidade do Império hipertrofiado se sustentar politicamente e a inadequação de suas estruturas políticas para lidar com o seu tamanho territorial e econômico. Para Ferdinand Lot a economia romana era "fina camada de economia monetária sob profunda economia natural" (LOT, 1982, p. 167). Ainda entre os franceses, mas no início dos anos 60, em uma outra obra de síntese, Roger Remondón, um Bizantinista, aponta o desajuste entre poder local (o patrimonialismo clientelístico) e o poder central (a burocracia Imperial), o contínuo desenvolvimento em separado das duas partes do Império (REMONDÓN, 1973, p. 169). Remondón expressa um dos aspectos do paradigma do Declínio e Queda; sua ênfase é dada à diferenciação entre os dois lados do Mediterrâneo, de forma a reservar à parte oriental outra História, a de Bizâncio. Esta separação se legitimava na obra de Remondón com a estabilização, a partir de 395, dos dois imperadores, e com a mudança da maneira como cada núcleo de poder lidou com os povos germânicos e hunos.

Até o início do século XX, a explicação que acentuava as causas externas - que apontavam o processo de transformação do tecido social romano devido ao contato com outros povos bárbaros, sejam os germânicos, sejam os hunos, sejam povos de ascendência iraniana, como os alanos, ou mesmo o Império Persa - estava ligada ao empreendimento de reconstruir a história destes povos. Ranke foi um dos proponentes fundamentais desta perspectiva, defendendo que a forma de sociedade dos povos germânicos e suas características culturais foram as grandes responsáveis pelas instituições dos Reinos que sucederam o Império na região ocidental do Mar Mediterrâneo. Sua explicação - e aqueles que a desenvolveram depois - fazia parte de um esforço intelectual alemão de recuperar, a partir da reconstrução documental realizada no XIX, o conjunto de povos germânicos e o seu processo migratório para a região da Europa: o Völkerwanderung (GOFFART, 1980, p. 16-29).

As diferenças de Ranke para com os historiadores franceses estão ligadas à formulação de uma outra questão derivada do problema das causas do Fim do Império. Esta questão derivada dizia respeito à natureza das sociedades que substituíram o Império Romano 
na Europa e se delineou num confronto entre as correntes ditas romanismo e germanismo. As duas correntes, que datam do século XIX, bus-cavam identificar o que era tributário da cultura romana e o que era devido à cultura germânica nas instituições, na cultura, na economia dos Reinos medievais, assim como no Império Carolíngio. É sig-nificativo, para o enquadramento da escrita da História no nacionalismo do mundo contemporâneo, o teor explícito em que o confronto entre estas correntes expressa o contexto histórico-político no qual ele se desenrolou. Os germanistas, em sua maioria entre os historia-dores alemães, acentuavam que a originalidade das instituições dos reinos germânicos era fruto das virtudes dos povos germânicos, num afã de fundamentar uma Germânia histórica (GOFFART, op. cit.) e que se impusera sobre o Ocidente ao longo da Idade Média. Do outro lado da fronteira, na França, alguns medievalistas e classicistas (como, por exemplo, Fustel de Coulanges) passaram a defender a ideia de que nos reinos germânicos houvera continuidade das instituições romanas, da qual a civilisation francesa seria a maior herdeira europeia.

Um emigrante Russo nos Estados Unidos da América, Mikhail Rostovtzeff ,com seu Social and Economic History of the Roman Empire de 1926, explorou uma nova dimensão do problema: o confronto entre as classes sociais, articulado à investigação econômica, como categoria explicativa do fim do Império Romano (ROSTOVTZEFF, 1967). Até então, esta dimensão, convenientemente ignorada pela Academia no Ocidente, seja a historiografia inglesa - preocupada com uma discussão racial da romanização dos bretões pelo Império (HINGLEY, 2005) - seja a francesa, ou a alemã (embora estivesse presente sem papel fundamental na visão delineada por Weber). Não um marxista, mas um espectador em primeira mão da Revolução Russa, Rostovtzeff, apontou como uma das razões da queda do Império as revoltas do exército contra os centros urbanos. Estas representavam um ataque dos camponeses, entre os quais se encontravam aqueles que se alistavam para o exército, contra a burguesia urbana. ${ }^{14}$ Ao que parece foi na Inglaterra que os trabalhos de Rostovtzeff tiveram mais influência, de maneira a surgirem historiadores preocupados com essa dimensão social e econômica do fim do Império. ${ }^{15} \mathrm{O}$ maior resultado dessa preocupação é The Later Roman Empire. 284-602 de A.H.M. Jones, publicado pela primeira vez em 1964. Embora publicado nos anos sessenta, o tra- 
balho de Jones pode ser considerado a culminação do impacto que o problema das lutas sociais colocou aos historiadores do início do século XX. Um trabalho de grande fôlego, tendo como objetivo fundamental reconstruir, a partir da observação documental direta e da problematização a partir da historiografia disponível até então, as estruturas administrativas, econômicas e sociais do Baixo Império a partir de Diocleciano. Em Jones, não uma suposta burguesia urbana, mas o crescimento da burocracia imperial tornava o Estado romano insustentável pela sua estrutura produtiva (JONES, 1992, p.1045).

Uma outra resposta formulada para a questão do Fim do Império se referia à desintegração da coisa pública e da cultura clássica sob influência do cristianismo. Datando do Renascimento, mas transformada em causa determinante por ninguém menos que Edward Gibbon (BROWN, 1982, p. 73-88), desdobrou-se numa ampla indagação sobre a transformação religiosa que se operara em todo o Mediterrâneo. No século XIX, estudiosos como Ernst Renan e Jacob Burckhardt se preocuparam com a institucionalização da religião cristã e seus efeitos. Num caso - Burckhardt - defendendo o cristianismo da responsabilidade pela degradação do senso político da elite romana (MAZZARINO, 1991, p. 140-141). Noutro - Renan - criticando os efeitos que tal institucionalização teve sobre a própria religião. O problema da transformação religiosa no império suscitava questões sobre a sociedade posterior à Queda. Historiadores, como Chris-topher Dawson, em sua obra The Making of Europe: an Introduction to the History of European Unity de 1932, explorava a ideia de que a uni-dade da Igreja cristã era a única força capaz de reunificar a Europa bárbara (BROWN, 2003, p.5).

Henri Pirenne, um historiador belga que se poderia dizer parte da corrente romanista, desenvolveu a ideia da continuidade econômica da unidade de Roma, para além da queda do Imperador no ocidente do Império. Partindo da investigação das relações comerciais e da conclusão a respeito da sua continuidade, ${ }^{16}$ ainda tendo como centro o Mediterrâneo, Pirenne postergou o fim do Império para o século VII, com as invasões árabes. Expressa fundamentalmente em 1937 no seu Maomé e Carlos Magno, sua visão apresentava a continuidade da influência romana nas sociedades que a sucederam. Esta 
influência era buscada para além das instituições ou dos discursos estatais, tentando construir uma totalidade social de dimensões mediterrânicas, a România (PIRENNE, 1970), e propondo uma compreensão mais ampla das interconexões comerciais. Estabelecia, assim, uma relação de centro e periferia entre Mediterrâneo e norte da Europa, deixando de lado a mesquinhez do recorte nacionalista, sob o qual se dava o tradicional debate entre romanismo e germanismo. Seu esforço em demonstrar a subordinação política das monarquias germânicas ao Imperador no oriente só pode ser entendido se contextualizado na ideia de uma unidade social que tinha como eixo o Mar mediterrâneo.

Tanto em Dawson, quanto em Pirenne, há a proposição de uma unidade europeia em articulação com a História do Império Romano. Embora ambos levassem em conta o processo de fragmentação da institucionalidade e as novas monarquias expressas na narrativa política, o primeiro colocava esta unidade em termos de uma cristandade, vendo aí o futuro da ideia de uma Europa, enquanto o segundo a colocava em termos econômicos.

Com a Primeira Guerra Mundial e de forma ainda mais acentuada, depois da Segunda, ganhou força uma versão francesa do germanismo. Nesta, afastava-se a explicação do fim do Império devido a uma causa interna, concentrando a estratégia explicativa na vitória germânica. Da mesma maneira, os povos germânicos passavam a ter maior presença na ordenação dos novos reinos europeus do século VI em diante. Esta presença maior, entretanto, resultava na ausência de instituições e de ordem social em tais reinos. Incapazes de construir uma civilização, os bárbaros teriam afundado as sociedades da porção ocidental do Império numa era das trevas, ideia da qual os mais notórios representantes foram Histoire littéraire des grands invasions germaniques de Pierre Courcelle, e L'Empire chrétien de André Pignaniol (WARD-PERKINS, 2005, p. 173; COURCELLE, 1955). A ideia de unidade europeia, que, como vimos, era pressuposto da estrutura das Formas e da História Universal, era contestada pela realidade do Imperialismo das potências europeias e das duas Guerras Mundiais.

Na mesma época, na Alemanha, no início de Literatura Europeia e Idade Média Latina, uma obra que se tornaria um clássico dos estu- 
dos literários, o filólogo Ernst Robert Curtius lamentava o estado do ensino de História nas nações europeias do início do século XX:

(...) nosso estudo pressupõe uma interpretação histórica da Europa. A Europa é apenas um nome, uma "expressão geográfica" (como dizia da Itália, Metternich), se não, apenas um conceito histórico. Para tal fim, todavia, de nada serve a história de nossos antiquados livros didáticos. Para eles não existe absolutamente história europeia, mas apenas a presença simultânea de histórias desvinculadas de povos e de Estados. Tomando-se como ponto de vista mitos e ideologias nacionais, ensina-se de maneira isolada e artificial a história das "grandes potências" de ontem e de hoje. Decompõem-se assim a Europa em áreas ou pedaços de espaço. Além da divisão em Antiguidade, Idade Média e Idade Moderna, ela também se subdivide em períodos de tempo. (...) Não tem sido diversa a situação na Inglaterra e na França. Mas a Alemanha passara por uma derrota e uma revolução. Podia ter tirado proveito e reformado o ensino de História...(...) A europeização do panorama histórico tornou-se atualmente uma necessidade política, e não só para a Alemanha (CURTIUS, 1996, p. 37-38).

Ernst Curtius buscava associar à Romania de Pirenne uma dimensão cultural e literária, das quais seriam tributárias não apenas as culturas de línguas latinas da Europa, mas também as de ascendência germânica. Não parte, todavia, de uma transposição direta, e sim da preocupação com o processo compreensivo hermenêutico através do qual a cultura da Antiguidade foi apropriada e reconfigurada pelas sociedades medievais. Tal processo também foi realizado pelas nações europeias a partir da cultura latina medieval. Em uma passagem em que se apoia no historiador Ernst Troeslch (na qual este último defende que a tomada do poder efetivo, embora não de direito, por Pepino de Herstal sobre a dinastia merovíngia, em 687 d.C. seria o marco do início do Mundo Moderno), explicita essa relação:

(...) nosso mundo Europeu não repousa "na aceitação nem na superação da Antiguidade, mas numa ligação geral e ao mes- 
mo tempo consciente com ela. O mundo europeu compõe-se de antigo e moderno. (...) a Modernidade se encontra impregnada e condicionada intimamente, em todos os sentidos à cultura, tradição, organização jurídica e estatal, língua filosofia e arte antigas. Apesar de um espirito totalmente novo e próprio. É isso que dá ao Mundo Europeu sua profundidade, plenitude, complexidade e mobilidade e, ao mesmo tempo, a tendência para o pensamento histórico e para a auto-análise histórica." (...) O começo do "Mundo Moderno" deve se fixar por volta de 675. Está "profundamente separado" do antigo, ainda que ligado a ele "em memória e continuidade histórica conscientes". Portanto uma continuidade, ou seja, uma conexão vital e homogênea que atenua esse profundo abismo (CURTIUS, 1996, p. 52). ${ }^{17}$

O programa de Curtius de europeização do panorama histórico busca a valorização de uma concepção humanística de conhecimento, em oposição ao chauvinismo nacionalista de sua época. ${ }^{18}$ Ainda assim, por mais sofisticado e cuidadoso que seja ao colocar os parâmetros dessa herança, em comparação com as outras culturas - como, por exemplo, a apreensão árabe dessa mesma herança, este programa reconstrói as identificações de Modernidade com Europa, e de Antiguidade com Império Romano, tendo em vista uma especificidade europeia, (CURTIUS, 1996, p. 54).

No pós-guerra, após os momentos iniciais de expiação historiográfica das "ações germânicas", a ideia de uma Romania ganharia força, seja econômica, seja cristã, seja Latina. No contexto de reconstrução de Europa - em meio ao Plano Marshall e a Guerra Fria - Santo Mazzarino escreveu seu Fim do Mundo Antigo. Àquelas passagens, já comentadas aqui, adicionava uma investigação dos usos que historiadores do início do XX fizeram da noção de decadência, influenciados pelas visões organicistas de Oswald Spengler e Ortega Y Gasset (MAZZARINO, 1991, p. 205-214). Ficava clara a presença da desilusão com a belle époque na historiografia do entre-guerras.

$\mathrm{Na}$ conclusão de seu ensaio, após apresentar algumas novas ideias que insinuavam um outro fim para o Império, colocava uma advertência: 
Até que ponto a revalorização da poesia e da arte do baixo império pode se estender às manifestações sociais e políticas do mesmo período? (...) estendendo estes pressupostos às manifestações de toda a vida do baixo império, corremos o risco de perder de vista o aspecto central de um de nossos problemas: ou seja, a barbarização da parte ocidental do império romano por volta do século V e a perda da Síria e do Egito no século VII. Podemos e, ousaria dizer, devemos recusar o termo "decadência" no que diz respeito à literatura e à arte no baixo império; podemos, por certa pruderie, evitar o termo no que diz respeito a outros fenômenos da vida neste período; mas não é lícito condenar sem apelação os historiadores que insistem na crise do império em termos políticos e sociais. A queda do império no Ocidente está sempre aí a advertir-nos que um mundo gótico, merovíngio, longobardo tomou a sucessão da Espanha, da Gália, da Itália romanas tardias (MAZZARINO, 1991, p. 220).

\section{III - Roma não acabou?}

Em 1999, era possível ler na introdução de uma coleção de ensaios, ${ }^{19}$ com contribuições de importantes historiadores do fim da antiguidade e início da Idade Média, as seguintes palavras: (...) "chegou a hora de pesquisadores, estudantes e o público educado em geral tratarem o período entre 250 e 800 d.C como um distinto e bem decisivo período da história, que se sustenta sozinho (BOWERSOCK, BROWN, GRABAR, 2001, p. ix)"'. Essas palavras preparavam a argumentação para a proposição da necessidade de um novo recorte cronológico para os estudos desse período: a Antiguidade Tardia.

Primordialmente parece válido pensar a Antiguidade Tardia como a proposta de uma nova Forma, uma vez que ostenta toda a arbitrariedade das antigas. Esta Forma, em linhas gerais, consolidou-se a partir de um conjunto de estudos feitos nas décadas mais recentes realizados a partir de outras perspectivas metodológicas, dentre as quais o que se tornou comum chamar nos anos oitenta de História 
Cultural (HUNT,1992). Houve uma grande influência, primeiro da História da Arte e, nos anos recentes, da Teoria Literária e dos Estudos Culturais, ${ }^{20}$ que desembocaram em novas abordagens da documentação do período. Hoje, no começo do século XXI, já há quem denomine essa corrente de nova ortodoxia ${ }^{21}$ e, para os fins dessa investigação, é preciso então que se opere uma definição das características dessa nova ortodoxia.

A pré-história desta Forma envolve um austríaco, um francês e um irlandês. Ward-Perkins (WARD-PERKINS, 2005) chama a atenção para a precedência germânica no surgimento do termo Antiguidade Tardia. Sob influência da obra do austríaco Alois Riegl sobre his-tória da arte do Baixo Império, Die spätrömische Kunst-Industrie nach den fundein osterreich-Ungarn (algo como A arte e a indústria tardo-romanas de acordo com achados na Áustria e Hungria), de 1901, surgiu o termo Spätantike (Antiguidade Tardia) que passou a ser utilizado por alguns historiadores também no entre-guerras. Porém, como se pode ver em Santo Mazzarino (MAZZARINO, 1991, p. 218-220), a importância de Riegl não está restrita à questão terminológica. Seu trabalho foi fundamental para uma revalorização da arte do período, de maneira que esta passasse a ser julgada com critérios próprios. Estes estudos foram realizados num contexto de transformação dos critérios da própria produção e crítica artística e literária do começo do século XX. Isto é, sob o forte impacto do modernismo, que historicizou a importância da mimesis na arte e dos padrões clássicos da arte europeia engendrando a valorização do abstrato na crítica estética. ${ }^{22}$

Na França, Henri-Irenne Marrou também teria contribuído para o surgimento do termo L'Antiquité tardive, com sua Retratactio, de 1949, uma obra na qual refuta sua própria defesa da ideia de decadência da cultura literária antiga, que expressara em Saint Augustine e la fin de la culture antique de 1938 (ROBERTS, 1989, p.3-4). L'Antiquité tardive francesa, embora tenha criado um espaço intelectual no que diz respeito ao estudo da cultura do período, ainda disputa espaço com as Formas do quadripartismo na Academia francesa.

É possível também associar esta valorização da arte e da cultura literária do Baixo Império, a par com a valorização da arte e da literatura medievais (lembremos de Ernst Curtius), com a visão da historiografia do Pós-guerra. Os historiadores desse período coloca- 
vam toda a responsabilidade pelo desaparecimento da cultura antiga nos invasores, o que de alguma maneira afastava a visão de um declínio da cultura e thes permitia pensar em termos das possibilidades e transformações que ainda teriam estado abertas à civilização romana.

Mas é com o irlandês que a Antiguidade Tardia se consolidou. Os trabalhos de Peter Brown exploraram uma perspectiva de história cultural e das práticas culturais, tentando esboçar as transformações nas formas de sentir o mundo que se operaram no período que vai de Marco Aurélio até Carlos Magno. Mas estas formas de sentir não são aquilo que os historiadores franceses na órbita da tradição da Revista Annales talvez chamassem de mentalidades. Peter Brown não buscava encontrar uma estrutura unificada das práticas culturais de longa duração, comum a todos os membros de uma sociedade; sua atenção se focava mais nos processos em transformação do que com a especificação de estruturas mentais típicas. Partindo do quadro geral de Henri Pirenne, seu eixo central de investigação se iniciou pela religiosidade tardo-romana, desdobrando-se no das relações com o corpo. ${ }^{23}$

Brown, a partir daí, desenvolveu uma perspectiva de continuidade social e cultural, na qual transformações profundas se operam. Isso se conjuga com uma perspectiva comparativa entre romanos latinos, o oriente do Império e os impérios vizinhos. E é esta operação historiográfica, de ampliar o escopo geográfico para incluir não apenas o Império do Oriente, mas também o Persa e a formação do Império árabe que sustenta a consolidação na língua inglesa do termo Late Antiquity. Num livro de caráter ensaístico, World of late antiquity, de 1971, Brown recusava de partida a perspectiva de decadência:

É muito fácil escrever sobre o mundo da Antiguidade Tardia como se ele fosse meramente um conto melancólico de 'Declínio e Queda": do fim do Império Romano, visto pela perspectiva do Ocidente; do Império Persa, Sassânida, visto pela perspectiva do Irã. (...) Olhando para o mundo da Antiguidade tardia, nós somos pegos entre a contemplação culpada das ruínas ancestrais e as aclamações excitadas do novo crescimento (BROWN, 1995, p. 7). 
O desenhar desta perspectiva é gradual, mas profundamente coerente ao longo de toda a obra deste autor. Desde suas tentativas de síntese, The world of Late Antiquity (BROWN, 1995), passando por sua contribuição para a coleção História da vida privada (BROWN, 1990a), e culminando em seu esforço mais acabado, The Rise of Western Christendom. Triumph and Diversity, Ad 200-1000 (BROWN, 2003). Assim, pensa a constituição da cristandade a partir do impacto da ascensão ao poder local e central dos bispos sobre comunidades culturais heterogêneas, a cultura como modus vivendi e as trocas entre sentimentos religiosos no oriente e na Pérsia. O diferencial da Antiguidade Tardia de Brown é que busca transcender não apenas os termos cronológicos, mas também os geográficos e sociais, e até mesmo civilizacionais.

É com Peter Brown que se pode apontar uma crise do para-digma, embora esta não seja imediatamente perceptível nem para o próprio. Interessante notar que, embora tenha estudado na Inglaterra (com muita proximidade de Arnaldo Momigliano, outro historiador preocupado com complicadas transformações culturais), foi a partir do fim dos anos setenta, conforme se aproxima mais e mais da Academia estadunidense, que suas propostas começam a ser sentidas.

A obra destes três autores - Riegl, Marrou e Brown - como uma espécie de revolução silenciosa, foi a base da tentativa de desconstrução do antigo paradigma. $\mathrm{Na}$ academia anglo-saxã, há muitos historiadores que contribuíram para a consolidação da Antiguidade Tardia na academia anglo-saxã. Um é Walter Goffart, com Barbarians and Romans (A.D. 418 - 584) The techiniques of accommodation, de 1980. Para este historiador canadense, a violência dos povos bárbaros sempre fora acompanhada de um esforço de inserção e participação no Império. Concentrando-se na questão das formas da continuidade da cobrança de impostos nos estados sucessores e desenvolvendo uma crítica dos usos historiográficos da instituição romana da hospitalitas, construiu as bases de um olhar que valoriza o processo mais amplo de acomodação das populações estrangeiras dentro do Império (GOFFART, 1980). A obra de Goffart é talvez uma das principais responsáveis pela atual vigilância terminológica quando se trata de se referir aos povos vindos de além Reno: a substituição do termo "in- 
vasores" pelo "migrantes", numa espécie de retorno à ideia do Völkwanderung. Mas isto é paradoxal, uma vez que Goffart é um dos principais críticos dessa imagem criada pelos historiadores alemães do XIX (GOFFART, 1980, p. 16-32). J.W.H.G. Liebeschuetz, um autor com distanciamento crítico do novo paradigma, acredita que o processo de diminuição do papel do Estado Imperial, de remilitarização da aristocracia e de privatização da ação militar só seria possível através da apropriação de terras pelos soldados e líderes bárbaros gradualmente aceitos por Walter Goffart (LIEBESCHUETZ, 1993, p. 267).

Averil Cameron, uma historiadora inglesa, desenvolveu um trabalho historiográfico sensível à necessidade de investigar as relações políticas estabelecidas no oriente do Império, tecendo em seus trabalhos a perspectiva de que o Império Romano com sede em Constantinopla ainda seria, por muito tempo, um horizonte político para os estados sucessores no ocidente. Mas sua atenção para com as relações políticas se fundava numa intuição sobre os processos de normatização da linguagem e da cultura, passando pelo cristianismo (CAMERON, 1994). É por este viés que entende a continuidade da força do poder imperial de Constantinopla sobre as regiões ocidentais do Mediterrâneo. "O quinto século viu um dos mais famosos não-eventos na história - a assim chamada 'queda do império romano no Ocidente’ que supostamente aconteceu em 476 d.C. (CAMERON, 1996, p. 33)".

Em 1993, ao procurar apresentar uma visão de conjunto dessa nova historiografia, Cameron justificava um novo recorte cronológico: “(...) a terminologia tem importância. Gostemos ou não dela, ela conforma nossas percepções, especialmente de assuntos controversos. O título deste livro, Mediterranean World in Late Antiquity, sugere em seus usos do termo 'Antiguidade Tardia' que algumas das bases da civilização clássica ainda sobreviveram, ainda que de forma fragmentada no ocidente bárbaro (CAMERON, 1996, p. 7-8)".

Em várias tradições intelectuais, a Antiguidade Tardia foi sendo aos poucos reconhecida e aceita como periodização e se fortaleceu o paradigma da continuidade. $\mathrm{Na}$ Itália, nos anos oitenta, a obra de Lelia Craco Ruggini (RUGGINI, 1983) e Domenico Vera (VERA, 1983) já apresentava essa perspectiva, mas sua força pode ser melhor 
avaliada no artigo de Andrea Giardina na Studi Storici (GIARDINA, 1999) que resultou anos depois num dossiê sobre a questão na mesma revista (STUDI STORICI, 2004). Na academia francesa, esse paradigma pode ser encontrado na obra de Claude Lepelley (LEPELLEY, 1969), André Chastagnol (CHASTAGNOL, 1985) e Jean-Michel Carrié (CARRIÉ \& ROUSSELLE, 1999), assim como no periódico L'Antiquite Tardive.

O impacto da Forma Antiguidade Tardia na academia brasileira, por sua vez, começou a ser sentido ao longo da década de noventa, quando a obra de autores como Brown e Marrou passou a ser lida e discutida nos estudos brasileiros sobre o Baixo Império e a Alta Idade Média. Mas só no final daquela década e nos primeiros anos do novo século que se pode dizer que o meio acadêmico passou a pensar e a criticar as categorias e conceitos associados a esta Forma, seja no estudo das formas de religiosidade cristã oriental e suas relações com o poder imperial (SILVA, 2001; SILVA, 2003), seja no processo de reorganização militar do Baixo Império (CARVALHO et al., 2008), seja na continuidade de parâmetros políticos romanos na soberania monárquica dos reinos sucessores de Roma (FRIGHETTO, 2000) ou na compreensão das ações contestatórias de grupos subordinados e sua linguagem religiosa (OLIVEIRA, 2008).

Nessa nova visão da passagem da Antiguidade para a Idade Média, portanto, conceitos estruturais da interpretação tradicional, como os de queda, de crise, de decadência e de invasões perderam seu espaço para outros como, continuidade cultural, migrações, poder local, a noção de România. Um novo paradigma se insinua, propondo como problema central as interconexões da região do Mediterrâneo, no qual as transformações são muito menos abruptas. É uma clara situação de crise de um paradigma interpretativo.

Ao se observar também o contexto político no qual se desenvolve esse novo paradigma, não é surpresa ver que as perspectivas de Peter Brown tenham sido formuladas em meio ao pós-colonia-lismo do final dos anos sessenta, momento em que havia a situação sociopolítica mais adequada para a redescoberta da cultura antiga tardia, tão menosprezada pelos parâmetros clássicos, já que se tratava de uma época de valorização da cultura "primitiva", de subversão do pensamento antropológico em favor do colonizado, de descoberta da história da periferia (DAVIES, 1995, p. 30-66; MILLES, 1999, p.1-2.) 
Chegando mais próximos de nossos dias, a consolidação desse novo paradigma se dá após o fim da Guerra Fria, da vitória sen-tida como definitiva de um Império ${ }^{24}$ (mas que só após 1999 e 2001 se apresenta explicitamente como um), numa atmosfera de globalização e intensas migrações populacionais.

Um exercício como esse, tentando relacionar o contexto político ou cultural à dinâmica específica dos sabores da pesquisa histórica, não intenta relacionar de maneira linear uma coisa à outra. $\mathrm{O}$ que se busca aqui é estabelecer parâmetros para situar o novo patamar da historiografia, a consolidação da Antiguidade Tardia como campo de pesquisa, em relação a hoje. Não esquecendo que, entre o contexto e as explicações historiográficas, há inúmeras mediações, é incrível como essa História do Império Antigo ressoa também uma História do presente.

Assim, a partir da relação do contexto político com as correntes intelectuais contemporâneas, pode-se situar a construção do projeto intelectual da Antiguidade Tardia. É em meio aos Estudos Culturais e, principalmente, com sua institucionalização na Academia dos EUA - e tudo que este processo significou em termos de compartimentação e fragmentação da pesquisa em nichos especializados (DAVIES, 1995, p. 155-161) - que se entende a força da consolidação dessa novidade. Ao mesmo tempo, no campo próprio das avaliações e do juízo dos historiadores, a Antiguidade Tardia apresenta uma tendência ao relativismo, muitas vezes descuidando dos processos de dominação e de exploração que acompanham as transformações culturais das sociedades do Mediterrâneo Antigo. ${ }^{25}$ Ward-Perkins vê, não sem motivo, na imagem simpática para com os bárbaros germânicos e no realce de suas trocas culturais com Roma, presentes na nova historiografia, uma íntima relação com a construção histórica da União Europeia (WARDPERKINS, 2005, p. 174). Mas até para um de seus maiores críticos, esta nova Forma apresenta pontos positivos:

Houve definitivamente ganhos do estudo dos séculos V ao VIII como parte da Antiguidade, ao invés da Idade Média, mesmo no Ocidente, onde eu argumentei que o modelo de um período contínuo e próspero se encaixa mal. (...) O mundo antigo tende a ser visto como um todo, e historiadores que o estudam são usualmente bem informados sobre tendências 
que afetam o todo do império, e utilizam comparações e contrastes para indicar o que é específico a respeito de uma região particular. No entanto, esta visão ampla e inclusiva se estreita uma vez que entramos na "Idade Média" - Eu muitas vezes me espantei ao perceber o quão pouco alguns distintos estudiosos da Britânia e da Itália pós-romanas sabem sobre o vizinho Reino franco, a despeito da riqueza de suas fontes. "Os estudos "medievais" tendem a se mover do presente para trás, procurando as origens dos Estados Nacionais da Europa, e ao fazer isso, eles frequentemente se tornam algo paroquiais no seu foco. A "Antiguidade Tardia” que se move para frente, a partir do Mundo Romano, oferece um cenário muito mais amplo e cosmopolita. (WARD-PERKINS, 2005, p.181-182).

Essa nova interpretação historiográfica recusou as noções de queda/decadência e crise. Para isso, foi necessário que a historiografia reconhecesse cada uma destas noções em sua historicidade e na sua potencialidade como categorias ou conceitos históricos. Conforme esse trabalho de refinamento conceitual foi operado, houve desdobramentos profundos do ponto de vista da conceitualização de certas interpretações dadas como óbvias. O resultado foi o delineamento de um novo paradigma explicativo, o da continuidade cultural, que veio associado a uma nova Forma da História, a Antiguidade Tardia. Nesse espírito, Peter Heather, em sua obra mais polêmica, embora veja a dimensão da ruptura política e militar como desencadeadoras de uma reestruturação social e enfatize a diferença entre a sociedade romana e a sociedade medieval, reconhece o quanto esse novo paradigma e a Forma Antiguidade Tardia resultaram em melhor compreensão da cultura e da sociedade ao redor do Mediterrâneo e da profundidade do processo de transformação nesse período (HEATHER, 2006). Assim, se há algum mérito nesta obra, é fornecer uma visão de totalidade para os estudos das sociedades do período entre III até VIII d.C., tendo os fluxos, trocas e conflitos do Mediterrâneo (HORDEN \& PURCELL, 2000) como eixo de investigação que mostra o anacronismo e eurocentrismo que existia no paradigma anterior com as divisões projetadas entre "Oriente" e "Ocidente".

\section{Late antiquity as a Form of History}

Anos 90, Porto Alegre, v. 16, n. 30, p. 77-108, dez. 2009 


\title{
Antiguidade tardia como forma da História
}

\begin{abstract}
This work consists of an investigation which aims to examine the issue of the opposing explanatory paradigm used to explain the end of Antiquity: the rise of Late Antiquity, a new Form of History, and the Fall of Roman Empire. In the last thirty years, this vision has been progressively opposed by historians of several affiliations, who suggest from a lessening of the impact caused by the Empire disruption, up to the complete neglect of this disruption. Structural concepts of the traditional interpretation, like crisis, decadence and Germanic invasions, give room for others, like the idea of Romania continuity and the barbarian people accommodation. This article tries to understand in what measure the end of the twentieth century influenced this change.
\end{abstract}

Keywords: Historiography. Late Antiquity. Roman Empire. Theory of History.

\section{Notas}

${ }^{1}$ Smith, Neil. Uneven development. New York, Basil Blackwell, 1994.

${ }^{2}$ A Introdução de Max Weber para a coletânea de seus estudos sobre sociologia das religiões, que no Brasil foi publicada como introdução às antigas edições do seu Ética Protestante e "Espírito" do Capitalismo, é emblemática porque Weber, assumidamente um liberal na política e tido por muitos como o melhor formulador de uma explicação não marxista da origem e funcionamento do Capitalismo, ali afirma este paradigma que relaciona modernidade com capitalismo em toda sua coerência e consequência, para depois se colocar como questão o porquê deste desenvolvimento da sociedade moderna (WEBER, 1992).

${ }^{3} \mathrm{E}$, às vezes, é motivo de orgulho que o pensamento historiográfico brasileiro seja também um departamento francês ultramar (CAPELATO et al., 1995).

${ }^{4}$ Cf. a problematização de Ernst Curtius do recorte Idade Média (CURTIUS, 1996, p. 53-57).

${ }^{5}$ No que diz respeito à Idade Antiga, o artigo de Guarinello procede um exame de suas incongruências e seus usos que termina com um revelador mini-manifesto: "Por fim, a história daquele mundo [o Mundo Antigo] é uma História interessante, ainda que não seja a história antiga do mundo. Vale a pena estudá-la, mas creio que deva ser transformada para atender às necessidades do presente. Ela deve libertar-se das formas que se tornaram anacrônicas. (GUARINELLO, 2003)".

${ }^{6} \mathrm{O}$ debate entre Antigos e Modernos tem um papel cultural - pelo menos no âmbito da formulação de categorias e ideias - central para que essas formas laicas da história se consolidassem na consciência histórica europeia (DEJEAN, 2005).

${ }^{7}$ Aqui, também não se pode esquecer o importante papel que a ideia de progresso teve como categoria de compreensão do mundo, mundo este que "progredia" tecnicamente, e criava uma ideia quantitativa e cartesiana de tempo (BENJAMIN, 


\section{Uiran Gebara da Silva}

1996; SARTRE, 1973, p. 158, n.32), que estruturava a hierarquia ascendente das Formas num continuum contabilizável de anos.

${ }^{8}$ Ver a crítica de G.E.M de Ste.Croix ao processo de orientalização dos Romanos de Constantinopla. (STE.CROIX, 1998, p. 7-9).

${ }^{9}$ Criticando este tipo de atitude, cf. Carlo Guinzburg (GUINZBURG, 2002).

${ }^{10}$ Mas não Agostinho, que desvincula o destino do Estado do Juízo de Deus, de acordo Peter Brown (BROWN, 2005, p. 373-389).

${ }^{11}$ Essa estrutura de eras ficava cada vez mais elástica, já que o mundo teimava em não acabar.

${ }^{12} \mathrm{O}$ que, de acordo com Thomas Kuhn, para a ciência, é algo muito saudável num debate científico no período normal de um paradigma.

${ }^{13}$ Perry Anderson realiza uma síntese dessa perspectiva (ANDERSON, 2000. p. 88-98).

${ }^{14} \mathrm{Cf}$. a crítica da ideia de associação solidária entre exército e camponeses (MAZZARINO, 1991) e à ideia de burguesia romana (STE.CROIX, 1998, p. 463).

${ }^{15}$ Pesavam sobre a historiografia francesa e alemã as questões político-institucionais. Burckhardt desenvolvera uma espécie de história cultural sem seguidores e, na França, apenas Georges Sorel - sem real reconhecimento entre os historiadores acadêmicos - tentara uma explicação nestes termos. Karl Kautsky - de quem se pode dizer o mesmo - também o fizera na Alemanha. Os passos iniciais da Revista Annales seriam no campo da cultura e das mentalidades, antes de convergir para esta direção (DOSSE, 1994).

${ }^{16}$ Tese revista hoje em dia (BROWN,2003, p.12-13; VAN DAM, 1992).

${ }^{17}$ Grifos do próprio Curtius.

${ }^{18} \mathrm{Na}$ mesma época, Erich Auerbach, outro filólogo de tradição humanista alemã, porém judeu, expressou preocupações incrivelmente semelhantes (AUERBACH, 2007, p. 357-374).

${ }^{19}$ Interpreting Late antiquity: essays on the post classical world - uma versão reduzida do Harvard's Guide to Late Antiquity.

${ }^{20}$ Cf. a introdução Richard Milles para Constructing Identities in Late Antiquity (MILLES, 1999).

${ }^{21}$ Expressão cunhada por Brian Ward-Perkins em um esboço do primeiro capítulo, denominado 'The new orthodoxies', mimeo, do seu The Fall of Rome: and the end of civilization. No entanto, na publicação ele só utiliza uma vez este termo (WARDPERKINS, 2005, p. 87).

${ }^{22}$ Cf. Para essa mudança de critérios na arte, (MAZZARINO, op. cit.), De A. Warburg a E.H. Gombrich: notas sobre um problema de método (GUINZBURG, 1999. p. 41-93) e ainda do mesmo autor: Além do exotismo: Picasso e Warburg (GUINZBURG, 2002, p. 118-136).

${ }^{23}$ Para o desenvolvimento de uma nova perspectiva no trato da religiosidade, pode-se seguir seu trajeto que vai da Biografia de Agostinho, Augustine of Hippo: a biography, de 1967 (BROWN, 2005), passando por uma coletânea de ensaios muito rica para ver os

Anos 90, Porto Alegre, v. 16, n. 30, p. 77-108, dez. 2009 


\section{Antiguidade tardia como forma da História}

débitos de Brown para com Gibbon e Pirenne, Society and the holy in Late Antiquity, de 1982 (BROWN, 1982) $e$ The cult of the saints: its rise and function in latin christianity, de 1981(BROWN, 1982); para a questão do corpo, seu Corpo e sociedade: o homem, a mulher e a renúncia sexual no inicio do cristianismo, de 1988 (BROWN, 1990b).

24 "Não se pode, portanto, dizer sem mais que os Estados Unidos começaram sua carreira de potência como um império tradicional. Mas podemos retirar as aspas (sempre implícitas), pois também é disso que se trata, um império que se alastrou pelo continente espetando postos militares nos territórios conquistados, tanto para melhor defendê-los, quanto para explorá-los economicamente" (ARANTES, 2007, p. 123). Para uma perspectiva que não identifica o império contemporâneo com a entidade política do Estado estadunidense, mas com o todo do sistema capitalista, cf. (NEGRI, 2003).

${ }^{25}$ Exatamente o que Ste.Croix aponta em Peter Brown. (STE.CROIX, 1998, p. 583, n. 24 ).

\section{Referências}

ANDERSON, Benedict. Nação e consciência nacional. São Paulo: Ática, 1989.

ANDERSON, Perry. Passagens da Antiguidade ao Feudalismo. São Paulo: Brasiliense, 2000.

ARANTES, Paulo. Extinção. São Paulo: Boitempo, 2007.

AUERBACH, Erich. Ensaios de Literatura Ocidental. São Paulo: Duas Cidades, 2007.

BEARD, Mary et HENDERSON, John. Antiguidade Clássica. Uma brevíssima introdução. Rio de janeiro: Zahar, 1998.

BENJAMIN, Walter. Sobre o conceito de história. In: Obras Escolbidas. Magia e técnica, arte e política. São Paulo: Brasiliense, 1996, p. 222-232.

BERNAL, Martin. A imagem da Grécia Antiga como uma ferramenta para o colonialismo e para a hegemonia europeia. In: Funari, P. P. A. (Org.) Repensando o Mundo Antigo. Campinas: IFCH/UNICAMP, 2005. Coleção Textos Didáticos.

BOWERSOCK, G. BROWN, P. GRABAR, O. Interpreting Late antiquity: essays on the post classical world. Cambridge and London: Belknap, 2001.

BROWN, Peter. Santo Agostinho. Uma Biografia. Peter Brown. Rio de Janeiro: Record, 2004. . Society and the holy in Late Antiquity. London: Faber and Faber, 1982.

. The cult of the saints: its rise and function in latin christianity. Chicago: The University of Chicago, 1982.

Anos 90, Porto Alegre, v. 16, n. 30, p. 77-108, dez. 2009 


\section{Uiran Gebara da Silva}

- Antiguidade Tardia. In: Veyne, Paul. História da vida privada - do império romano ao ano mil. vol. I. Cia das letras: São Paulo, 1990.

. Corpo e sociedade: o homem, a mulher e a renúncia sexual no início do cristianismo. Rio de Janeiro: Zahar, 1990.

. The world of Late Antiquity. Thames and Hudson, Londres, 1995.

. The making of Late Antiquity. Massachusetts: Harvard University, 1997.

. The Rise of Western Christendom. Triumph and Diversity, Ad 200-1000. Oxford:

Blackwell, 2003.

BURKE, Peter. A revolução francesa da historiografia: a Escola dos Annales (1929-1989). São Paulo: EDUNESP, 1992.

. (Org.) A escrita da história: novas perspectivas. São Paulo: EDUNESP, 1992.

CAMERON, Averil. Christianity and the rhetoric of empire : the development of christian discourse. Berkeley: University of California, 1994.

. The Mediterranean World in Late Antiquity AD 395-600. London: Routledge,

1993.

CAMERON, Averil, GARNSEY, Peter. The Cambridge Ancient History. Vol. XIII, The Late Empire AD 337-425. Cambridge: Cambridge University, 1998.

CAPELATO, Maria Helena Rolim. et al. A Escola Uspiana de História. In: Produção histórica no Brasil. 1985-1994. São Paulo: FFLCH, 1995.

CARRIÉ, Jean-Michel, ROUSSELLE, Aline. L'Empire romain en mutation, des Sévères à Constantin. Paris: Seuil, 1999.

CARVALHO, Margarida Maria de, et al. Barbarização do exército romano e renovação historiográfica: novas perspectivas sobre o tema. História: Questões \& Debates. Curitiba, UFPR, n. 48/49, 2008, p. 147-16., CHASTAGNOL, Andre. L'évolution politique, sociale et économique du monde romain de Dioclétien à Julien: La mise en place du régime du Bas-Empire (284-363), Paris: SEDES, 1985.

CHESNEAUX, Jean. Devemos fazer tabula raza do passado? Sobre a história e historiadores. São Paulo: Ática, 1995.

COURCELLE, Pierre. História Literária das Grandes Invasões Germânicas. Rio de Janeiro: Vozes, 1955.

CURTIUS, Ernst Robert. Literatura Europeia e Idade Média Latina. São Paulo: Hucitec, 1996.

DAVIES, Ioan. Cultural Studies and Beyond. Fragments of Empire. New York: Routledge, 1995. 


\section{Antiguidade tardia como forma da História}

DEJEAN, Joan. Antigos contra Modernos. As Guerras Culturais e a construção de um fin de siècle. Rio de Janeiro: Civilização Brasileira, 2005.

DOSSE, François. A história em migalhas. São Paulo: Ensaio, 1994.

ESTEPA, Carlos. La transición del esclavismo al feudalismo. Madrid: Akal, 1980.

FINLEY, M. I. Ancient Economy. Berkeley: University of California, 1999.

FRIGHETTO, Renan. Cultura e Poder na Antiguidade Tardia Ocidental. Curitiba: Juruá, 2000.

GARNSEY, Peter, SALLER, Richard. The Roman Empire. London: Duckworth, 1987.

GEARY, Patrick. O Mito das Nações. A invenção do Nacionalismo. São Paulo: Conrad, 2005.

GIARDINA, Andrea. Esplosione di tardoantico. Studi Storici. Roma: Fondazione Instituto Gramsci, anno 40, n. 1, 1999, p. 157-180.

GOFFART, Walter. Barbarians and Romans (A.D.418-584) The techiniques of accommodation. Princeton: Princeton University, 1980.

GOMBRICH, Ernst. História da Arte. Rio de Janeiro: Zahar, 1999.

GUARINELLO, Norberto Luiz. Memória Coletiva e História Científica. In: Revista Brasileira de História. São Paulo, v. 14, n. 28, 1994, p. 180-193.

. Uma morfologia da História: as formas da História Antiga. In: Politeia História e Sociedade. Vitória da Conquista, v. 3, n. 1, 2003, p. 41-62.

História científica, história contemporânea e história cotidiana. In: Revista Brasileira de História. São Paulo, v. 26, n. 52, 2006, p.227-248.

. Escravos sem senhores: escravidão, trabalho e poder no mundo romano.

In: Revista Brasileira de História. São Paulo, v. 24, n. 48, 2004, p.13-38.

GUINZBURG, Carlo. Mitos, emblemas e sinais. São Paulo: Cia. das Letras, 1999.

- Relações de força: História, retórica, prova. São Paulo: Cia. das Letras, 2002.

. O fio e os rastros. Verdadeiro, falso, fictício. São Paulo: Cia. das Letras, 2007.

HEATHER, Peter. The Fall of the roman Empire. A new History of Rome and the barbarians. New York: Oxford University, 2006.

HINGLEY, Richard. Concepções de Roma: uma perspectiva inglesa. In: Funari, P.P.A. (Org.) Repensando o Mundo Antigo. Campinas: IFCH/UNICAMP, 2005. Coleção Textos Didáticos.

HOBSBAWM, Eric. A curiosa história da Europa. In: Sobre História. São Paulo: Cia das Letras, 2000, p. 232-244. 


\section{Uiran Gebara da Silva}

HORDEN, Peregrine e PURCELL, Nicholas. The Corrupting Sea. A study of Mediterranean History. Oxford: Blackwell, 2000.

JONES, A.H.M. The Later Roman Empire.284-602. Baltimore: Johns Hopkins, 1992.

KUHN, Thomas S. A Estrutura das Revolucões Científicas. São Paulo: Perspectiva, 2006.

LEPELLEY, Claude. L'empire romain et le christianisme. Paris: Flammarion, 1969.

LIEBESCHUETZ, J.H.W.G. The End of the Roman army in the western empire. In: RICH, John e SHIPLEY, Graham. War and society in the Roman world. London: Routledge, 1993, p. 265-276.

LOT, Ferdinand. O fim do mundo antigo e o princípios da Idade Média. Lisboa: Edições 70, 1982.

MARROU, Henry-Irenne. História da Educação na Antiguidade. São Paulo: HerderEDUSP, 1969.

MATTHEWS, John F. Western aristocracies and imperial court. Ad 364-425. N. York: Oxford,1990.

MAZZARINO, S. O fim do Mundo Antigo. São Paulo: Martins Fontes, 1991.

MILLES, Richard (Org). Constructing Identiies in Late Antiquity. London: Routledge, 1999.

MOMIGLIANO, A. As raízes clássicas da historiografia moderna. Bauru: Edusc, 2002.

MUSSET, Lucien. Las Invasiones. Las Oleadas Germanicas. Barcelona: Labor, 1967.

NEGRI, Antonio. Cinco lições sobre Império. Rio de Janeiro: DP\&A, 2003.

PIRENNE, Henri. Maomé e Carlos Magno. Dom Quixote: Lisboa, 1970.

OLIVEIRA, J. C. M. Poder, religião e violência popular no Império Romano Tardio: os motins de Calama de junho de 408 d.C. In: História. Questões e Debates, v. 48/49, 2008, p. 165-192.

RÉMONDON, Roger. La crisis del Imperio Romano - de Marco Aurelio a Anastasio. Barcelona: Nueva Clio, 1984.

ROBERTS, M. The Jeweled Style. Poetry and Poetics in Late Antiquity. Ithaca: Cornel University, 1989.

ROSTOVTZEFF, Mikhail I. História de Roma. Rio de Janeiro: Zahar, 1967.

RUGGINI, Lellia Cracco. Le associazioni de mestieri in età imperiale: ruolo político e coscienza professionale. In: Vera, Domenico (Org.) La societá del Basso Impero. Roma: Laterza, 1983. 


\section{Antiguidade tardia como forma da História}

SALIBA, Elias Thomé. As luzes e as fadas: reflexões sobre o marxismo e as recentes tendências da historiografia. In: Coggiola, Osvaldo. Marx e Engels na História. São Paulo: Xamã, 1996, p. 39-50.

SARTRE, Jean-Paul. Questão de método. In: Os pensadores, v. XLV. São Paulo: Abril Cultural, 1973.

SCHIAVONE, Aldo. Uma história rompida. Roma antiga e o Ocidente moderno. São Paulo: Edusp, 2005.

SILVA, Gilvan Ventura da. O fim do Mundo Antigo: uma discussão historiográfica. Mirabilia, Brasil, v. 1, 2001, p. 1-10.

. Reis, santos e feiticeiros: Constâncio II e os fundamentos misticos da basileia (337-361).

Vitória: Edufes, 2003.

STE. CROIX, G.E.M. de. The class strugle in the Ancient Greek world. Ithaca: Cornell University, 1998.

STONE, Lawrence. O ressurgimento da narrativa: reflexões sobre uma nova velha história. In: Revista de História. Campinas: IFCH/UNICAMP, 1991.

STUDI STORICI. Roma: Fondazione Instituto Gramsci, anno 45, n. 1, 2004.

VAN DAM, R. The Pirenne thesis and fifth century Gaul. In: DRINKWATER, J. and ELTON, H. Fifth-Century Gaul: A Crisis of Identity? Cambridge: Cambridge University, 1992. p. 321-333.

VERA, Domenico. (Org.) La societá del Basso Impero. Roma: Laterza, 1983.

VEYNE, Paul. O Império Romano. In: História da vida privada - do império romano ao ano mil. v. 1, São Paulo: Cia. das Letras, 1990.

WARD-PERKINS, Brian. The Fall of Rome: and the end of civilization. New York: Oxford University, 2005.

WEBER, Max. As causas sociais da decadência da cultura antiga. In: COHN, Gabriel. (Org.) Weber. São Paulo: Ática, 1983.

. Ensayos sobre sociología de la religión . v. I. Madrid: Taurus, 1992. . Introducción. In: WEBER, Max (1992, p. 11-24).

WICKHAM, Chris. The other transition: from the Ancient World to Feudalism. In: Past and Present, 103, Oxford, 1984. 